\title{
Research on the Perfection of Incentive Mechanism of Human Resource Management in Colleges under Network Age
}

\author{
Xiaoping $\mathrm{Ma}^{1 \text {, a }}$ \\ ${ }^{1}$ Nanyang Institute of Technology, Nanyang, Henan, 473004 \\ a email
}

Keywords: Network Era; University; Human Resource Management

\begin{abstract}
With the changing of the times, the obsolete human resource management concept in our country, the imperfect management mechanism, and the imperfection of the resources supporting facilities in the university, the weak degree of information and other factors have restricted the healthy development of modern human resources management in our country. With the network era, people's way of thinking and way of life have undergone tremendous changes, but also to our university human resources management incentive mechanism has brought new thinking, which will also be on our colleges and universities the improvement of human resource management incentive mechanism provides strong support.
\end{abstract}

\section{Introduction}

With the continuous development of network technology, China's human resources management has had a profound impact. Human resource management in Colleges is the core content of the school personnel work, but also the allocation of talent in China and human resources, a scientific management of a method. In the current social background, China's teaching staff in the construction and development process, the school should pay more attention to optimize the human resources management mechanism in Colleges, so as to improve the enthusiasm of our college staff enthusiasm and enthusiasm. The construction of a scientific university human resources management mechanism, in addition to attract more talents, but also improve the horny staff of the professional teaching level and overall quality, make full use of the functions of each job, so as to the university's educational activities and teaching Level to lay a solid foundation.

\section{The Characteristics of Human Resources Management in Colleges and the Importance of Intense Mechanism}

University of human resources in fact refers to our colleges and universities engaged in education and teaching or administrative work of the staff. As a result of its educational institutions, this type of human resources in other human resources have different places: first is that it has a strong independence and creativity; university human resources due to living in educational institutions, most of them Is a good cultural quality, so this type of people have the judgments and opinions on the affairs, and they can consciously use their own knowledge and culture [1]. Second, in Colleges, as China has entered the Internet era, people's way of thinking has undergone tremendous changes, people for teachers of this type of industry there are different views, so compared to the past, with greater liquidity; That is, compared to the college system in the past, the university's human resources needs are gradually diversified; because the university human resources are high cultural quality and social status, the standard of living is also relatively high compared to ordinary people living standards , And this also led to the improvement of the demand level of this class of people, coupled with the arrival of the Internet age, people's basic necessities have undergone tremendous changes, so the demand for human resources in Colleges also showed a diversified Development trend [2].

But also because of the characteristics of human resources in Colleges in China, it is more prominent in Colleges to encourage the mechanism in the importance of human resources 
management. The so-called incentive mechanism refers to the human resources in the university, the full development of it, and by meeting the individual needs for the purpose of stimulating people's desire to meet, so that people can move towards a different direction of a means. According to a study by a professor of management in the United States, it was found that when a person was not motivated, he could only play about $20 \%$ to $30 \%$ of the person's ability, but when the incentive Was raised to about $80 \%$. And the way of encouragement can be through the material, spiritual and other aspects, some people can overcome the morale of morale and so on. The use of this incentive mechanism in Colleges in our country can effectively improve the overall quality and teaching level of teachers and administrative personnel, stimulate the enthusiasm and creativity of their work, and can show a strong organizational cohesion.

\section{The Problems in the Human Resources Management Mechanism in Colleges}

In the social background of our country, the traditional incentive mechanism of human resource management is presented in a single way, and the concrete manifestation is as follows: First, in most cases, the way of material stimulation adopted by our university, but in the spirit of the incentive is more Lack of, and when the staff and staff to make some of the contributions of the time, the school only to a certain degree of material incentives, and this way long-term people will have a sense of disgust, and such a sense of disgust will seriously affect the staff Mood, thus affecting their work enthusiasm and work mood, leading to the decline in teaching quality [3]. Second, the lack of incentives to individualize. As the faculty and staff of the university, the vast majority of the living standards are relatively good, with the content of the faculty and the nature of the work of different, so to a certain extent, teachers more hope is not just material incentives, More need to be some need to be able to truly meet the individual needs of the reward, but in reality did not appear this situation.

In the era of China's Internet, many colleges and universities for the evaluation of staff and staff assessment, because still follow the traditional evaluation system, so there are some unreasonable, unscientific situation, and in the management of colleges and universities, often only teachers But also did not attach importance to the quality of teaching work; coupled with the colleges and universities in our country which did not fully understand the characteristics of different academic fields, using the same standards for teachers in different areas of teaching and research work to assess; The assessment system is not included in the title of the teacher, the title for life-long effective; assessment formal, not from Germany to work and other aspects of teachers to quantify the assessment; failed to fully consider the teacher's moral quality, awareness, psychological quality and spirit of collaboration And other aspects of the factors, the level of teachers to conduct a scientific evaluation; In addition, due to the level of teaching staff in the academic level, ability level, the nature of work and job responsibilities and other aspects of differences, unified assessment criteria difficult to develop and implement [4].

In the background of our university, the vast majority of colleges and universities in China still do not face up to the mechanism of human competition, and its main performance is: First, in our country colleges and universities for the appointment mechanism of teachers to be improved. And this is also due to the impact of traditional ideas. And in Colleges, for the employment mechanism people do not have too many ideas, the specific college appointment system also needs to be based on the new era to further improve. However, in the actual situation, China is the vast majority of colleges and universities in Colleges due to the lack of college staff, the use of a life-long phenomenon, which also led to part of the crowd's loose psychology. Followed by the performance management is not in the teacher's salary system associated, reward and punishment is not clearly defined, and this is one of the main factors.

\section{The Construction of Human Resources Management Mechanism in Colleges}

To constantly improve the cultural incentive mechanism, we must attach importance to the role of teachers in the spirit of the incentive, and through the combination of spiritual and material 
incentives, combined with college staff have a high cultural quality and level Demand characteristics, in the campus campus to actively create a good working environment and academic environment. And in Colleges, management should give teachers more opportunities for personal development, such as studying abroad, further study, the teacher's personal level effectively improve, not only to improve the school's teaching level, but also to stimulate the teacher's honor So that it has a greater power in the spirit to achieve self-worth. It enables teachers to maintain a relatively good teaching state for a long time. The second is through the understanding of different levels of education, job forms and job functions of individual needs, according to the actual needs of faculty and staff to use different forms of incentives to rationalize the incentive. Especially for young teachers, to their life problems, career development and so on to be concerned about, to create a good learning environment and growth conditions.

Want to improve the standards of assessment in Colleges in China must be on the workload of teachers to assess, not only the number of teachers to review the number of work, but also to the work that the quantitative and transparent assessment; and in specific aspects According to the nature of the horny work and job functions to different assessment of different indicators, and in accordance with the relevant indicators to develop a personal assessment program, and in the process to ensure that the assessment process is open and transparent, the real implementation of the assessment of protection; To improve the evaluation mechanism in Colleges. And in the mechanism of the existence of specific indicators can be scientific research topics, published academic papers, so that teachers can clear the work, so as to continuously improve the quality of teaching in Colleges. The last is to promote the evaluation system of colleges and universities, the development of the evaluation system to improve the development of the former requires a comprehensive and open faculty of the work ability, performance evaluation, earnestly reward or punishment; the latter, The long-term development of workers as the focus, through scientific evaluation, found its advantages and disadvantages, through appropriate measures to encourage self-appreciation, strengthen its sense of honor and enthusiasm, so as to effectively improve the quality of teaching, work level.

In our university, the establishment of the incentive mechanism of human resources can not be separated from the competition mechanism. Only through this combination of merit and excitement can we make the functions and working efficiency of the faculty and staff to the maximum, so as to constantly improve the manpower of the university Resource construction level. And this is mainly in the implementation of job hiring in Colleges, and actively introduce the market mechanism, according to the job responsibilities of personnel selection, so as to ensure the overall quality of teachers within the college, and only in order to better maintain the level of teaching ; Second is to have the staff in the university to give the work of the incentive measures, so that reward and punishment is clear, and give teachers more opportunities for development, strengthen the sense of competition of staff and staff, making it more active in teaching work, Improve its teaching quality and efficiency.

\section{References}

[1] Liu Ming received. The incentive mechanism in the use of human resources management [J]. Management Manager, 2017, (04): 173

[2] Yang Yang. How to construct the incentive mechanism of human resources management in Colleges [J]. Human Resources Development, 2017, (02): 47-48.

[3] Li Jinmei. "Internet $+"$ under the era of human resources management of the new trends and countermeasures analysis [J]. Business economy, 2017, (01): 95-97.

[4] Li Xiaojuan.Management Psychology in the construction project human resources management application [J]. Engineering Technology Research, 2017, (01): 126-129 